\title{
Usos e apropriações das culturas populares nas aulas de educação física de uma escola pública
}

http://dx.doi.org/10.11606/1807-5509201900030453
Bethânia Alves Costa ZANDOMÍNEGUE,***

André da Silva MELLO"
*Universidade Federal do Espírito Santo, Vitória, ES, Brasil.

*Universidade Vila Velha, Vila Velha, ES,

Brasil.

\section{Resumo}

Objetiva compreender os usos e as apropriações que os alunos e professores de uma escola pública fazem das manifestações das culturas populares no contexto das aulas de Educação Física e no cotidiano de uma escola pública. Para tanto, utiliza os Estudos com o Cotidiano como pressuposto teórico-metodológico, em que os dados foram produzidos com os diferentes praticantes do contexto escolar, professores, alunos, equipe pedagógica e comunidade local, por meio de diferentes fontes, diário de campo, narrativas, entrevistas e outros. 0 resultado denota os seguintes usos e apropriações das culturas populares: relação da cultura local com a global; valorização da autonomia e da participação dos alunos na construção do saber; produção do "conhecimento em redes"; sensação de pertencimento à comunidade escolar.

Palavras-Chave: Estudos com o Cotidiano; Redes de Saberes; Ensino Fundamental; Protagonismo do Aluno.

\section{Introdução}

Os debates atuais em torno da educação brasileira situam os desafios que perpassam esse campo em uma dimensão que vai além da modernização do ensino, do investimento em novas tecnologias da informação ou da inadequação dos métodos de aprendizagem. Focalizam, principalmente, as transformações rápidas pelas quais o mundo passa e o distanciamento da escola em relação a essas mudanças, que se revela na dificuldade de aprendizagem, no desinteresse por parte dos alunos em relação aos conteúdos estabelecidos pela escola e nos altos índices de reprovação e evasão escolar.

De acordo com Veiga-Neto ${ }^{1}$, o modelo de educação formal, evidenciado na sociedade brasileira, cria uma sensação de "estranhamento" naqueles que vivem diariamente a escola. São os praticantes do cotidiano, que, muitas vezes, não se reconhecem nesse contexto, gerando um estado de "crise". Para o autor, a crise pressupóe um estado de desequilíbrio, que pode ser apontado como um dos motivos pelos quais se tem discutido a necessidade de se repensar a escola a partir das relações entre educação e as diferentes culturas, enfatizando sua necessidade de "enraizamento" social.

Nesse contexto, alguns autores da Educação e da Educação Física ${ }^{1-3}$ indicam a necessidade de estudos que apontem caminhos de como estreitar a relação entre a educação e as diferentes culturas, de forma a possibilitar que o conhecimento produzido se desdobre dentro do espaço escolar como estratégia para a melhoria da qualidade das aulas e o fortalecimento das relaçóes entre a escola e a comunidade local.

Outro fator relevante para que a escola dialogue com as demandas dos tempos atuais está associado à valorização das ações práticas dos estudantes que, a todo o momento, ressignificam o espaço e tempo escolar, num processo de reinvenção cotidiana, em que as suas experiências culturais se afloram e proporcionam oportunidades de relações e de trocas no contexto de formação.

$\mathrm{Na}$ Educação Física Escolar, percebemos, nas produções acadêmicas da área ${ }^{4-6}$ e no cotidiano das práticas pedagógicas desenvolvidas nesse contexto, a ênfase na abordagem de determinados conteúdos, em especial das modalidades esportivas, omitindo ou negligenciando o vasto campo de conhecimentos relativos às culturas populares. A própria constituição física dos espaços destinados a essa disciplina, configurada por quadras poliesportivas, em 
grande parte das escolas, induz à abordagem dos esportes, em detrimento de outras possibilidades de manifestações das culturas. Não se trata, portanto, de negar o esporte como conteúdo da Educação Física, mas questionar a sua primazia em relação às outras manifestações culturais. De acordo com FARIA 5 " [...] Ainda que outros conteúdos penetrem as aulas, o esporte compõe a Educação Física, cada vez mais, como elemento central" (p. 132).

Visando contribuir com o processo de estreitamento da relação entre escola e comunidade, este estudo busca compreender os usos e as apropriações que os praticantes do cotidiano de uma escola pública fazem das manifestaçóes provenientes das culturas populares nas aulas de Educação Física e em outros espaços e tempos escolares.

Para a compreensão do conceito de Cultura Popular, destacamos haver inúmeras abordagens e maneiras de interpretá-lo. Dentre as várias possibilidades existentes, focalizaremos as reflexões desenvolvidas por CERTEAU ${ }^{7,8}$, para quem a cultura só faz sentido para os que dela se apropriam, imprimindo usos e significados específicos. Desse modo, a cultura popular é entendida por CERTEAU $^{7}$ como uma cultura comum produzida por pessoas comuns em sua vida cotidiana, em suas inventividades diárias, a partir do "uso" e das "maneiras de viver" com os produtos impostos pelos diversos contextos, sociais, políticos, culturais, ou ainda, um modo de resistência à situação de dominação.

Nesse universo, existe a hipótese de haver um movimento de circularidade $^{2}$, ou seja, uma interlocução, feita de influências recíprocas entre as diferentes "classes"a sociais, que nos leva a compreender o caráter dinâmico e de constantes transformações pelas quais passam os processos de consumo e produção de culturas. Nessa perspectiva, destacamos a ampliação do conceito de cultura e a possibilidade de pensar a cultura popular para além de sua compreensão em modelos culturais tradicionais ${ }^{7-10}$.

Desse modo, o conceito de cultura popular empreendido neste estudo se balizará nas influências recíprocas entre as diferentes culturas, na inventividade, nas estratégias de afirmação de identidades, na convivência do dia a dia, nos movimentos protagonizados pelos alunos e professores para tornar significantes os produtos culturais que lhes são apresentados para o consumo, no contexto das aulas de Educação Física de uma escola pública. Pautados nos pressupostos de CERTEAU $^{7}$, para quem o consumo produtivo ${ }^{b}$ das culturas denota as diversas artes e as maneiras de fazer das pessoas, adotaremos, ao longo do texto, o termo culturas populares no plural. De acordo com o Fórum de Comunidades Tradicionais, movimento que há 10 anos luta pelo direito ao território, à saúde, à educação diferenciada e a valorização das tradições das comunidades, as culturas populares devem ser tratadas no plural, pois elas apresentam diferenças, riquezas, diversidades e pluralidades que inviabilizam a sua abordagem no singular. Buscamos compreender os sentidos produzidos por meio dos conteúdos e temáticas das manifestações populares desenvolvidos nas aulas de Educação Física e identificamos que as culturas populares se materializam como elementos privilegiados pelos professores, expressos nos jogos, nos desenhos, nas danças produzidas pelos alunos durante as aulas que, ao extrapolarem para outros contextos escolares, afirmam-se reveladores da representatividade e afeição dos alunos pela disciplina e pela escola.

\section{Método}

Para alcançar os objetivos propostos nesta pesquisa, utilizamos os Estudos com o Cotidiano ${ }^{7}$ como pressuposto teórico-metodológico. Vivenciamos com os praticantes, consumidores e produtores de culturas, o cotidiano das práticas pedagógicas das aulas de Educação Física no contexto escolar.

Os Estudos com o Cotidiano investigam as redes ${ }^{c}$ de saberes e fazeres que são tecidas pelos sujeitos em sua vida ordinária. Tecer conhecimento em rede significa empreender a produção do conhecimento na dinâmica de interação. Trata-se, portanto, do que é construído com os outros: as pessoas, as normas, os objetos, as sensações, as imagens, em uma conexão que cresce por todos os lados e em todas as direçôes, provocando modificações nos contextos em que se manifestam ${ }^{11}$.

Do ponto de vista epistemológico, essa perspectiva de pesquisa rompe com os modelos de investigação que separam o sujeito do objeto, em busca da padronização e da divisão dos elementos (modelo cartesiano). Contrário a essa lógica, o processo 
investigativo tecido nos Estudos com o Cotidiano ocorre com o sujeito, em sua relação com o objeto, nos sentidos construídos, nos vestígios deixados e na capacidade de produzir conhecimentos. Nesse viés, valoriza-se o heterogêneo, a pluralidade e o complexo. Busca-se articular os elementos entre si, em um processo que se constrói e se transforma constantemente no decorrer da pesquisa. Para Alves ${ }^{12}$, "ao invés de dividir, para analisar, será preciso multiplicar - as teorias, os fatos, as fontes, os métodos, etc. Mais que isso, será necessário, entre eles, estabelecer redes de múltiplas e também complexas relaçôes" (p. 26).

Nesse contexto, o cotidiano é compreendido por nós a partir de $\mathrm{CeRTEAu}^{7}$, que o entende como o lugar da vida comum que, envolto em redes complexas, ultrapassa o que imaginamos ou estamos acostumados a ver ou perceber dele. São as questóes do dia a dia, os significados que as pessoas constroem a partir de seus hábitos, as banalidades, o trivial e, paradoxalmente, o inovador que revelam as culturas produzidas nas artes e maneiras de fazer dos sujeitos. Suas inventividades, as táticas ${ }^{\mathrm{d}}$ utilizadas e valorizadas, diante das estratégias imperativas sobrepostas a ele.

Nossa concepção teórico-metodológica percebe a escola como espaço de açóes, criações, representações, significados, invençôes, estratégias e táticas, que são compreendidos no "estar com", "fazer com", "vivenciar com", "refletir com", para estabelecer relações complexas na produção do conhecimento em redes de colaboração.

Para tanto, estabelecemos alguns critérios para a escolha dos nossos colaboradores. Delimitamos que fosse uma escola pública que atendesse alunos do primeiro ao quinto ano do ensino fundamental, que dialogasse com as culturas da comunidade local e desenvolvesse os conteúdos e as temáticas relacionadas às culturas populares nas aulas de Educação Física, no decorrer do período de

\section{Resultados e Discussão}

A EMEF C. J. foi inaugurada em 2005, em decorrência do aumento da demanda de matrículas na região. Enquanto providenciava a construção de uma nova sede escolar, a Prefeitura Municipal alugou um prédio que não foi projetado para funcionar como escola. Devido a isso, apresentava muitos problemas de ordem estrutural, como a falta realização da pesquisa. Desse modo, a EMEF C. J. correspondeu aos requisitos estabelecidos, além de estar situada na Serra/ES, município em que $80 \%$ de seus habitantes são migrantes de diferentes locais do Estado e do País, tornando-se um contexto de diversificadas expressōes culturais ${ }^{14}$.

Procuramos vivenciar a escola, inseridos em seu cotidiano durante cinco meses. Realizamos visitas ao nosso contexto de pesquisa três vezes por semana. Nesse processo, constatamos que as 13 turmas de $1^{\circ}$ ao $5^{\circ}$ ano do ensino fundamental, do turno matutino, tinham aulas de Educação Física três vezes por semana, com os professores Marcos e Josi $\mathrm{i}^{\mathrm{i}}$. Optamos por acompanhar as turmas de $3^{\mathrm{a}} \mathrm{e} 4^{\mathrm{a}}$ séries atendidas nos dias de nossas visitas à escola. Desse modo, as turmas da $3^{a} \mathrm{~A}, 3^{\mathrm{a}} \mathrm{C}, 3^{\mathrm{a}} \mathrm{D}, 3^{\mathrm{a}} \mathrm{E}, 4^{\mathrm{a}} \mathrm{A}, 4^{\mathrm{a}} \mathrm{B}$ e $4^{\mathrm{a}} \mathrm{C}$ foram especialmente acompanhadas por nós.

Como instrumentos para a coleta de dados foram utilizados: observações participantes das aulas de Educação Física, sistematizadas em diário de campo; entrevistas semi-estruturadas com a coordenadora de turno, com as professoras regentes das turmas $4^{a} \mathrm{~A}$ e $4^{\mathrm{a}} \mathrm{B}$ e com um dos professores de Educação Física; entrevistas em grupo focal, com oito alunos representantes das turmas do turno matutino: $3^{\mathrm{a}}$ $\mathrm{A}, 3^{\mathrm{a}} \mathrm{B}, 3^{\mathrm{a}} \mathrm{C}, 3^{\mathrm{a}} \mathrm{D}, 3^{\mathrm{a}} \mathrm{E}, 4^{\mathrm{a}} \mathrm{B}$ e $4^{\mathrm{a}} \mathrm{C}$; documentos produzidos na ação pedagógica (planejamentos, projetos, textos e desenhos feitos pelos alunos); imagens iconográficas e vídeos. Além disso, registramos vários depoimentos da outra professora de Educação Física, que foram estruturados como narrativas .

Os sujeitos da pesquisa foram: os dois professores de Educação Física do turno matutino; as professoras regentes das turmas $4^{\mathrm{a}} \mathrm{A}$ e $4^{\mathrm{a}} \mathrm{B}$, Vera e Kátia; os alunos das turmas $3^{a} \mathrm{~A}, 3^{\mathrm{a}} \mathrm{B}, 3^{\mathrm{a}} \mathrm{C}$, $3^{\mathrm{a}} \mathrm{D}, 3^{\mathrm{a}} \mathrm{E}, 4^{\mathrm{a}} \mathrm{A}, 4^{\mathrm{a}} \mathrm{B}$ e $4^{\mathrm{a}} \mathrm{C}$ e a coordenadora de turno. Esta pesquisa foi submetida e aprovada pelo Comitê de Ética em Pesquisa da Universidade Federal do Espírito Santo.

de um espaço amplo para a prática de Educação Física. Por ser um espaço adaptado, a escola se restringiu ao atendimento de $1^{\mathrm{a}}$ a $4^{\mathrm{a}}$ séries do ensino fundamentalf ${ }^{f}$.

Dado o quantitativo de turmas, a Educação Física é ministrada por dois professores. As aulas são realizadas em duas turmas simultaneamente, 
que dividem o mesmo espaço para a mediação. Por esse motivo, os professores organizam a proposta de trabalho de maneira conjunta, abordando o mesmo tema em suas aulas, mas que nem sempre coincidem quanto às séries, o que se apresenta, além da falta de espaço físico apropriado às aulas de Educação Física, como outro desafio para as suas práticas pedagógicas.

Ao iniciarmos nossa inserção no contexto escolar chamou-nos a atenção, os indícios da relação estabelecida entre as culturas populares e a Educação Física. No terraço do prédio, espaço destinado às aulas de Educação Física, as paredes são decoradas com artes em grafite, manifestação cultural daqueles alunos valorizada nas aulas. As imagens trazem os vestígios da prática cotidiana que acontece ali. Há predominância de desenhos com o nome da escola, o que sugere a afeição dos alunos com esse espaço. Alguns exprimem manifestações oriundas das culturas populares tratadas nas aulas de Educação Física, como a dança de rua, que representa a dança comumente, praticada por eles e, os jogos. Essas e outras pistas ${ }^{10}$ identificadas nas representaçóes dos desenhos sinalizam que os alunos dessa escola possuem forte relação com a disciplina Educação Física e com os conteúdos por ela trabalhados.

A organização pedagógica das aulas de Educação Física da EMEF C. J. se caracteriza por uma distribuição trimestral dos conteúdos no ano letivo. Durante o ano de nossa inserção na escola, a estruturação dessa disciplina se deu da seguinte forma: no primeiro trimestre, os professores desenvolveram um projeto sobre o lazer. De acordo com a narrativa da professora de Educação Física, esse projeto contribuiu para o encaminhamento da proposta do segundo trimestre do ano letivo, relativa às culturas populares brasileiras, que se estendeu até o final do terceiro trimestre:

O projeto sobre as culturas populares brasileira surgiu assim: no primeiro trimestre, a Educação Física começou a discutir o lazer. No decorrer desse processo, os alunos identificaram que havia determinadas brincadeiras que eram específicas de algum bairro, comunidade e utilizadas como forma de lazer local. Então comecei a conversar com as crianças das $3^{\mathrm{a}}$ e $4^{\mathrm{a}}$ séries sobre as características da cultura que identificam o nosso Estado e percebi que precisaria aprofundar o tema, quando uma aluna definiu o funk como uma dança típica do Estado. Outro aluno a contrariou, alegando ser o congo, e outros disseram ser a capoeira e o hip hop. Com essa discussão, pedimos que os alunos identificassem o que formava a cultura capixaba (JOSI - professora de Educação Física).

A culminância do projeto relacionado com as culturas populares brasileiras ocorreu na "Mostra Cultural Brasil de Norte a Sul". A professora Josi disse que o envolvimento dos alunos com essa temática nas aulas de Educação Física, e a participação deles nas tarefas propostas pela disciplina, contribuíram para que a direção pedagógica da escola idealizasse uma festa que envolvesse toda a comunidade escolar. A narrativa da professora de Educação Física fornece indícios de que os saberes relativos às culturas populares, desenvolvidos em suas aulas no decorrer do projeto, foram tecidos em consonância com a "metáfora da rede", sugerida por ALves ${ }^{13}$, em que uma ação leva à outra e, quando menos se espera, uma ampla estrutura de conhecimento se forma de maneira coletiva e contínua. A construção dessa rede também foi evidenciada na descrição do outro professor, Marcos, ao afirmar que as discussões empreendidas nas aulas de Educação Física, com os saberes trazidos pelos alunos, contribuíram na "tessitura do conhecimento":

Geralmente a gente inicia um trabalho fazendo um diagnóstico do que o aluno traz de conhecimento sobre o assunto e, a partir dali, a gente cria os eixos de discussão (MARCOS professor de Educação Física).

Pensar a rede como metáfora, compostas por "fios e nós", permite compreender que nada surge por acaso, que, de alguma forma, as coisas, as pessoas $\mathrm{e}$ as ações estão ligadas à complexidade do todo. A produção cotidiana na escola permitiu trançar um grande número de "fios", de forma complexa, em que o "emaranhado de ações, interações e retroações" na produção do saber delegou aos praticantes a condição de sujeitos, em um contexto que os institui e no qual são, ao mesmo tempo, instituintes ${ }^{16}$.

A constituição da rede de conhecimento sobre as culturas populares, na perspectiva anunciada por Morin ${ }^{16}$, em que tudo é tecido junto e simultaneamente ${ }^{\mathrm{g}}$, colaborou para que o projeto sobre as culturas populares extrapolasse o âmbito das aulas de Educação Física, constituindo relações que envolveram os diferentes praticantes do cotidiano escolar e a comunidade local, como demonstram as seguintes narrativas: 
Os alunos se envolveram muito, se identificaram com a temática, gostaram de descobrir as curiosidades [...], se encantaram com as histórias e com o trabalho que construíram [...] Os pais participaram diretamente em tudo o que era necessário fazer. Os materiais solicitados foram doados por eles [...], a pintura facial do dia da festa foi realizada por mães de alunos (VERA professora da $4^{\text {a }}$ série $A$ ).

A comunidade participou através do envolvimento dos pais e dos alunos. Houve realmente um grande interesse por parte de todos (SARA - coordenadora pedagógica).

Essa rede que foi se constituindo em torno do projeto, cujos eixos articuladores foram os conhecimentos culturais trazidos pelos alunos, valorizou os saberes locais e possibilitou a interrelação entre a escola e a comunidade.

$\mathrm{Na}$ Mostra Cultural, identificamos outras características que denotam o envolvimento dos alunos no processo de construção do conhecimento. As apresentaçóes culturais das diferentes regiōes do País, representadas por meio da música, dos modos de dançar, dos passos e dos figurinos foram elaboradas em parceria com os alunos, nas aulas de Educação Física. Os adereços que complementavam o visual, como o chapéu, a casaca, as sombrinhas de frevo, dentre outros, também foram produzidos por eles. Os alunos participaram da confecção do painel da Mostra, construíram um boneco de Olinda ${ }^{\mathrm{h}}$, tingiram os tecidos utilizados no figurino das danças, além de colaborar diretamente na pesquisa das músicas e nos penteados característicos. Os trabalhos expostos na Mostra tematizaram as culturas populares em suas diferentes manifestações e contemplaram a diversidade cultural do Brasil, expressa pelas danças (frevo, maculelê, carimbó, samba, dentre outras), pelas comidas típicas de cada região do País, pelos costumes, pelos aspectos históricos e geográficos, pelas brincadeiras, pelo artesanato e pelas músicas.

A Mostra Cultural apresentou os produtos, resultado de um processo que foi desenvolvido no cotidiano das aulas de Educação Física e se redimensionou como um projeto pedagógico da escola sobre as culturas populares, envolvendo todas as turmas dos turnos matutino e vespertino, os professores regentes, as professoras de Artes e de informática, a comunidade local e a equipe pedagógica. Nesse processo, os saberes populares valorizados pelos alunos, no diálogo com a cultura local e a nacional, motivaram a construção do conhecimento, que foi tecido em rede pelos praticantes daquela comunidade escolar.

Para a reflexão acerca das relaçôes que a escola estabelece com a comunidade, bem como o reconhecimento e a participação dos alunos no processo de construção dos saberes escolares, destacamos a valorização das culturas ordinárias produzidas pelos praticantes do cotidiano a partir de Certeau ${ }^{7}$. Para esse autor, é necessário irmos de encontro ao outro, sem nos conformarmos com aquilo que está dado a priori sobre ele. As reflexôes de Certeau nos ajudam a perceber o aluno como o outro no qual a escola deve ir ao seu encontro, tentando entender o que esse outro tem a dizer, sem a pretensão de prescrever, o tempo todo, o que ele deve fazer. Nesse sentido, CARVALHO ${ }^{17}$ afirma que o movimento de considerar a prática do outro favorece a ressignificação do espaço e tempo da escola a partir do outro e com ele, e não para ele.

As açôes pedagógicas que valorizam os procedimentos de criação encaminhados pela escola colaboram para o desenvolvimento dos sentidos, da percepção e ampliam a relação do sujeito com o mundo. A associação desses processos criativos às expressões culturais possibilita a reflexão, o gosto pelas artes e pela educação estética, que se produz na própria prática do fazer. Para CERTEAU ${ }^{15}$, há de se valorizar o caráter "estético" das práticas cotidianas, que se efetiva na ocasião. Trata-se de uma dimensão própria, de um estilo, uma criação singular do sujeito, traduzida na sua "arte de fazer". Essas açōes revelam o modo como o sujeito dá sentido à vida $\mathrm{e}$ às suas práticas.

Ao focalizarmos os sentidos construídos pelos praticantes do cotidiano, em suas relaçôes com as diferentes manifestações das culturas populares, explicitamos as suas tentativas de tornar a escola e as ações pedagógicas nela produzidas, um espaço identitário. São essas ações dos praticantes que, de maneira astuciosa, reconfiguram dia a dia as práticas curriculares e os permitem atuar como sujeitos ativos do seu processo de socialização ${ }^{3}$.

Em relação aos trabalhos desenvolvidos no cotidiano das aulas de Educação Física, destacamos indícios de diferentes usos e apropriaçōes da dança, manifestação das culturas populares valorizadas pela comunidade local, entre os diferentes turnos. No turno matutino, o trabalho com a dança é descrito pelo professor de Educação Física da seguinte maneira: 
O trabalho da professora do turno matutino envolve toda contextualização histórica, de cada exemplo de dança popular abordada, desde os pequenos detalhes, como o porquê de se dançar descalço, ou pegar o rosa com a boca, até o trabalho de equipe, de construção em grupo, com que os alunos se identificam bastante (MARCOS - professor de Educação Física).

Em sentido contrário, no turno vespertino, a dança é tratada de outra maneira, como descreve o mesmo professor:

\begin{abstract}
Atualmente, trabalho nessa escola nos dois turnos. Em relação à dança, que é algo que já vem sendo trabalhado pela professora da manhã há alguns anos, os alunos têm uma aceitação maior. [...] À tarde é diferente. Eu trabalho em parceria com a outra professora, que também desenvolve o conteúdo dança, mas parece que o interesse maior dela e dos alunos são as apresentações nos dias de festa [...] (MARCOS - professor de Educação Física).
\end{abstract}

Embora nossa perspectiva teórica valorize a heterogeneidade das práticas inventivas dos sujeitos praticantes do cotidiano, os produtos gerados das ações pedagógicas nos diferentes contextos propiciam algumas reflexões. As narrativas evidenciam diferentes tratos pedagógicos dados ao conteúdo dança popular no contexto das aulas de Educação Física na comunidade compartilhada e revelam a disparidade dos modos e maneiras de consumo produtivo da dança entre os turnos. No turno matutino, os sentidos produzidos pelos praticantes do cotidiano, nos usos e apropriações da dança no espaço e tempo escolar, permitem identificá-la como cultura popular. Ao observarmos a produção de conhecimentos relacionados com a dança no dia a dia das aulas de Educação Física do turno matutino, percebemos a preocupação da professora em contextualizar esse conteúdo de maneira histórica, social, econômica e cultural, bem como valorizar as produções que realiza com os alunos, os adereços, os passos, os figurinos e a pesquisa das músicas regionais. Ela produz, em conjunto com os alunos, sentidos singulares que favorecem o consumo produtivo da dança na perspectiva das culturas populares, aqui conceituada ${ }^{7}$.

No entanto, o uso e a apropriação desse conteúdo, no turno vespertino, assumem outra perspectiva de consumo produtivo e suscita questionamentos quanto aos "modos de fazer" que justifiquem essa prática na produção de sentidos das culturas populares. Percebemos que nesse contexto, o modo como os sujeitos (alunos e professores) se apropriam da dança nas aulas de Educação Física se estabelece a partir da compreensão que eles têm quanto ao papel social da escola. Sob o viés da escolarização, a dança se define como um conteúdo a ser ensinado pela escola, de forma sistematizada. Nesse sentido, sugere outra perspectiva, em que as culturas populares são "transplantadas" para o contexto educacional, sem preocupação com uma reflexão ou adequação dos conteúdos às características históricas e culturais da comunidade escolar. Para $\mathrm{ABIB}^{18}$ essas ações são superficiais e não superam a conotação "caricaturada" das culturas populares, predominante em muitas escolas.

O trato pedagógico da dança, no turno vespertino da EMEF C. J. não se difere daquilo que alguns autores, como MArques $^{19}$, Brasileiro ${ }^{20-22}$, FiamonCini ${ }^{23}$ e MORANDI $^{24}$ criticam sobre a dança na escola. A análise estabelecida a partir da perspectiva teórica desses autores indicou que a presença da dança na escola se dá, prioritariamente, na forma de apresentações em datas comemorativas, quando passos aleatórios são inseridos para que as crianças repitam mecanicamente até decorarem a sequência, sem estabelecerem reflexões pedagógicas acerca do conteúdo. BRASILEIRO ${ }^{20}$ afirma que, "[...] apesar da dança estar presente no espaço escolar, ela é, apenas, um elemento decorativo, sem reflexão como conhecimento para a formação dos alunos" (p. 78).

Em sentido contrário, a proposta do turno matutino explora o potencial educativo e cultural dessa manifestação popular, possibilitando aos alunos não apenas a prática desse conteúdo, mas também experiências significativas que valorizam as suas produçôes e os saberes da cultura local que possuem.

A coexistência de situações ambíguas presentes nesse contexto evidencia o caráter complexo e contraditório do cotidiano escolar e revelam as diferentes formas de consumo e produção de sentidos. Se, por um lado, o tratamento dado à dança obedece à lógica da escolarização, por outro, ele é dinâmico e profundo, explorando o potencial pedagógico que essa manifestação cultural oferece.

Para além das diferenças que a dança apresenta nos turnos matutino e vespertino, os usos e apropriações que os praticantes fazem dessa manifestação popular no cotidiano das práticas pedagógicas nas aulas de Educação Física, evidenciam a produção de diferentes sentidos, que repercutem nos diversos espaços e tempos praticados da escola. Identificamos que esse movimento, no recreio, nas escadas, nas salas de aula 
e nos corredores, cria redes de colaboração entre os alunos, que ressignificam constantemente o contexto vivenciado, como demonstram as suas falas:

Numa roda de funk, um entra, aí fica dançando, depois sai, aí vem o outro (JOÁO PEDRO aluno da $3^{\mathrm{a}} \mathrm{A}$, grupo focal).

Tem um trenzinho que é legal. A gente sai pela escola dançando (CARLOS - aluno da $3^{\mathrm{a}} \mathrm{B}$, grupo focal).

Os alunos movimentam a escola e criam seus espaços de mediação com as culturas populares da dança. Os professores usam de maneira astuciosa esse movimento para trabalhar com esse conteúdo em suas aulas. Dada a identificação dos alunos, o conteúdo dança extrapola a dimensão das aulas de Educação Física e ao domínio dos professores, como demonstram as descriçōes extraídas do diário de campo em diferentes momentos da inserção e a narrativa do professor de Educação Física:

Ao sinal do recreio, a turma da $4^{a} \mathrm{~A}$ desejou que aquele momento da aula se estendesse e pediu que a professora de Educação Física colocasse a música lá embaixo. $\mathrm{Na}$ sala dos professores, algumas professoras comentaram que os alunos desceram as escadas cantando e disseram que eles chegam na sala de aula, após a Educação Física, cantando as músicas, repetindo os refróes e as danças que vivenciam lá em cima [referindo-se ao terraço onde ocorrem as aulas de Educação Física] (DIÁRIO DE CAMPO).

Desse modo, o que marcou o momento do recreio foi a música que a professora Josi colocou pra tocar e fez com que os alunos dançassem. O estilo era Dança de Ruai e manifestava a identificação cultural das crianças (DIÁRIO DE CAMPO).

[...] se não tivesse esse trabalho em conjunto com a outra professora, que domina o conteúdo que eu não tenho tanta afinidade [...] provavelmente não o trabalharia. [...] só trabalho esse conteúdo [dança] por 'livre e espontânea pressão' dos alunos (MARCOS - professor de Educação Física, grifo nosso).

O professor Marcos traduz com o termo "pressão" aquilo que, de acordo com CerTEAU? entendemos como relação entre táticas e estratégias que permeiam o ambiente educacional. As táticas astuciosas dos alunos movimentam e "assombram" o lugar. Esse movimento do "fraco" favorece a conquista de novos espaços instituídos no "lugar de poder", que, nesse caso, é representado pelo professor. Sobre a relação entre estratégias e táticas, CERTEAU $^{7}$ descreve:
Traçam 'trajetórias indeterminadas', aparentemente desprovidas de sentidos porque não são coerentes com o espaço construído, escrito e pré-fabricado onde se movimentam. [...] essas 'trilhas' continuam heterogêneas aos sistemas onde se infiltram e onde esboçam as astúcias de interesses e de desejos diferentes. Elas circulam, vão e vêm, saem da linha e derivam num relevo imposto, ondulaçôes espumantes de um mar que se insinua entre os rochedos e os dédalos de uma ordem estabelecida (p. 97).

Esse movimento se evidencia quando, em um primeiro instante, os alunos agem taticamente, estabelecendo relações com o "poder". Nessa relação dialógica com a estratégia, os alunos adquirem credibilidade que, aos poucos, "implode" esse poder e constroem novos poderes, ou seja, outras estratégias. De acordo com CerTEAU ${ }^{7}$, a tática golpeia lance a lance a estratégia e, ao golpeála, institui outras estratégias. Esse é o movimento que, a nosso ver, estabelece "pressão" dos alunos sobre o contexto, conforme descreveu o professor Marcos.

São nas ações realizadas pelos praticantes do cotidiano que "nascem as possibilidades", que depois vão sendo institucionalizadas pela escola. Ao darem certo, essas ações acabam se consolidando como "novas" possibilidades de atuação profissional e/ou se transformam em projetos coletivos da escola. Portanto, de uma dimensão tática, ou seja, do uso astucioso do poder, se atinge um patamar mais abrangente. Ao valorizar as culturas populares como conhecimentos fundamentais daquele lugar, a escola passa a instituí-la como algo importante, ao ponto de se consolidar como um projeto coletivo. Por intermédio dessas reflexões, percebemos que, muito mais que "dicotomizar" a tática da estratégia, é possível perceber suas constantes inter-relações nos espaços e tempos do cotidiano escolar. Essa é a relação de estratégias e táticas que os alunos, professores e escola vivenciam o tempo inteiro. 
Dessa água regulada em princípio pelas redes institucionais que de fato ela vai aos poucos erodindo e deslocando, [...] não se trata, com efeito, de um líquido, circulando nos dispositivos do sólido, mas de movimentos diferentes, utilizando os elementos do terreno ${ }^{7}$ (p. 97-98).

Trabalhar com as danças populares é, de certa maneira, um desafio para muitos professores da escola. Apesar disso, alguns docentes não se eximem de valorizá-las no contexto de suas aulas, pois a reconhecem como elemento de forte identificação dos alunos daquela comunidade. Os professores, então, criam estratégias metodológicas para abordar o conteúdo. Ampliam as condições para uma produção coletiva do saber, delegando responsabilidades aos alunos no que se refere à construção de alternativas de ensino, nas quais todos estão enredados. Isso favorece o envolvimento e a participação deles, tornando-os praticantes do processo de ensino-aprendizagem e, muitas vezes, faz com que os próprios professores também sejam aprendizes e se sintam desafiados diante da novidade. Essa iniciativa, portanto, contribui para que as experiências dos alunos não se limitem à apenas àqueles conhecimentos que o professor domina. A narrativa do professor de Educação Física evidencia o desafio a que ele se submeteu ao trabalhar com as danças populares nas suas aulas:

Apesar de não dominar as danças populares, me oportunizei a trabalhar com elas porque gosto de dar exemplo para os meus alunos [...]. As crianças gostam de ver a gente produzindo junto. Isso faz com que eles se motivem a participar mais ativamente (MARCOS - professor de Educação Física).

A vivência das culturas populares na escola extrapola os espaços organizados e controlados pelos professores e direção, como as salas de aula. Elas se manifestam de forma autônoma e voluntária no cotidiano dos alunos, que aproveitam os "tempos livres" e as "brechas" concedidas pelos professores para vivenciar as manifestações culturais que lhes interessam. A narrativa da coordenadora de turno demonstra essa iniciativa dos alunos:

Nesses momentos informais como o recreio, os alunos demonstram o que aprenderam [...]. A dança é uma forma que eles encontram de estar demonstrando o que estão aprendendo. Quando não tem música, aparecem outras brincadeiras deles (SARA - coordenadora de turno).

Embora os movimentos táticos empreendidos pelos alunos, muitas vezes, atinjam o patamar de novas estratégias, nem sempre é possível capitalizar as suas ações e incorporá-las às práticas pedagógicas dos professores. Os alunos também aproveitam as "brechas" concedidas para burlar a ordem e subverter o poder instituído no lugar. Essas ações atravessam momentos ou aparecem em locais não propícios para elas, como na sala de aula, nos corredores, descendo as escadas, dentre outros. Portanto, no ambiente educacional, o modo como os praticantes se apropriam e transformam aquilo que lhes é dado, ou seja, a forma como produzem culturas, a partir do que lhes é oferecido, dentro e fora da escola, pode se configurar como desafio para esse contexto.

A descrição seguinte, extraída do diário de campo, evidencia uma das muitas situações enfrentadas no cotidiano das práticas pedagógicas, em que os próprios educadores são surpreendidos pelas açōes que brotam das "fissuras" identificadas pelos alunos no espaço e tempo da escola:

A professora Josi, convidou quatro meninos que assistiam as apresentaçóes, para compor a coreografia da dança com as meninas e os advertiu para que dançassem fazendo somente o que as meninas fizessem, e eles concordaram. Mas, no decorrer da apresentaçáo, eles começaram a rebolar com muito entusiasmo. As crianças da plateia gritavam. Foi um momento de muita euforia e alguns professores sinalizaram constrangimento com aquela situação. Um dos meninos que dançava, aproveitando-se da oportunidade, se jogou no chão simulando uma cena de sexo. Nesse momento, os outros meninos que assistiam de fora invadiram o local da apresentação e simularam movimentos de ato sexual juntamente com outros alunos. Quando a música acabou, foi um sentimento de alívio para os professores presentes (DIÁRIO DE CAMPO, grifo nosso).

Essas práticas espontâneas que atravessam e movimentam o espaço e tempo escolar configuram a dimensão do imponderável e do imprevisível que permeia esse contexto. Por mais 
que a escola seja um ambiente formal, submetido às normas e parâmetros que visam a exercer $o$ controle e a disciplina, a complexidade do seu cotidiano a torna não apenas espaço de saberes formais, mas de outros saberes praticados, que se articulam em redes complexas e plurais. Para Alves $^{12}$ :

A escola é, assim, também espaço, pois em movimento, expressão das 'táticas', lugar praticado, pleno de 'operaçōes', devidas a açōes de sujeitos históricos [...]. Esse espaço tenta se criar/fazer no próprio já apropriado, no lugar da ação estratégica do poder político que com uma regularidade, que poderíamos dizer assustadora, se atualiza para permanecer igual (p. 130).

O mergulho no cotidiano da EMEF C. J. nos permitiu observar que, embora haja uma valorização significativa dos saberes oriundos das culturas populares, devido ao grau de interesse que despertam nos alunos, os usos e apropriações desses saberes pelos professores não ocorrem de maneira tão harmônica. Percebemos que eles disputam o reconhecimento do trabalho que desenvolvem em suas disciplinas e utilizam as manifestações populares, especialmente aquelas estimadas pelos alunos, como as danças de rua, as músicas e o teatro, para atrair a atenção para o trabalho que desenvolvem. Ao ser capitalizada para o reconhecimento da ação pedagógica, materializada no aumento da representatividade com os alunos e com a equipe gestora da escola, o uso das manifestações provenientes das culturas populares não se restringe aos professores de Educação Física.

Pela possibilidade de apresentação para as famílias e para a comunidade escolar, o uso das manifestações populares extrapola o contexto das salas de aula, contribuindo para dar visibilidade aos trabalhos desenvolvidos pelos professores. Além disso, mobilizam os alunos, no que se refere ao envolvimento e dedicação deles nas atividades propostas. Constatamos que as manifestações de origem popular são usadas pelos professores não apenas pelo seu potencial educativo, mas também pelos seus interesses em atrair prestígio e reconhecimento para os trabalhos que realizam. A fala do professor Marcos e o relato extraído do diário de campo denotam que a utilização das manifestações oriundas das culturas populares não está circunscrita à Educação Física:
Nós temos aqui vários professores que, quando podem, se utilizam do teatro, da música e das danças populares. Sempre que tem algum evento, mesmo sabendo que a Educação Física vai preparar alguma apresentação, os professores regentes também preparam algo do tipo. É algo que é da escola mesmo, dos profissionais (MARCOS - professor de Educaçẫo Física).

Encontramos a professora Vera, da $4^{a} \mathrm{~A}$, ensaiando sua turma no refeitório para a comemoraçáo do dia de Açáo de Graças e para a apresentaçáo dos alunos no dia da formatura da turma. A frase da professora era: 'sintam a música!', reivindicando que seus alunos buscassem uma identificaçáo com a música para que pudessem construir uma dança. Observamos que o conteúdo Dança de Rua, que tem uma forte identificação das culturas populares locais, é abordado por outros professores, em outros contextos, que não apenas na/pela Educação Física. Isso sugere algo que vai em direção ao que é representativo para a escola. Vimos que os elementos das culturas populares movimentam a escola (DIÁRIO DE CAMPO).

Apesar do uso coletivo, a narrativa da professora Josi tenta demarcar o lugar de destaque da Educação Física na concepção dos projetos relacionados com as culturas populares na escola:

O que acontece muito aqui, na escola, até pela credibilidade que a Educação Física tem, é que ela puxa o tema e a professora de classe trabalha junto. Isso é diferente da maioria das escolas, que pedem ajuda ao professor de Educação Física, quando idealizam trabalhar com determinado tema. Aqui é o contrário, a Educação Física puxa o projeto e os outros entram (JOSI - professora de Educação Física).

De acordo com o relato da professora e com as práticas observadas no cotidiano da escola, percebemos a inversão de uma lógica historicamente instituída, onde a Educação Física se constitui como uma disciplina auxiliar de outras aprendizagens, em especial, as de cunho cognitivo. A sua função é, em grande parte, controlar o corpo para que os desígnios da razão não sejam prejudicados, ou seja, o corpo é o "outro" da razão que precisa ser docilizado ${ }^{25}$. No contexto vivenciado, mediado pelas 
manifestações das culturas populares, essa lógica se altera e as açôes empreendidas, inicialmente nas aulas de Educação Física, ganham uma dimensão institucional, compartilhadas por diversos professores.

Os movimentos astuciosos da professora de Educação Física, de certa maneira, contribuem para que as suas ideias se propaguem pela escola. Essas ideias, ao se espalharem, garantem-lhe um "capital simbólico"26. Ela age de maneira tática, no sentido de publicizar o que está fazendo, como evidencia a sua narrativa:

Quando estou fazendo algum projeto, eu já chego para o professor na porta, na hora de pegar o aluno ou na hora do recreio, nesses momentos não formais, e falo o que estou trabalhando. Muitas vezes, a professora vê o que a gente deixa escrito no quadro, porque eu tenho esse hábito de, quando inicio um conteúdo, eu registro no quadro da sala de aula dos alunos os temas ou temáticas que a gente pretende trabalhar (JOSI - professora de Educação Física).

Entretanto, a disputa pelo lugar, materializado na autoria dos projetos e na visibilidade das açôes, faz com que alguns professores não confiram crédito ao pioneirismo da Educação Física. Algumas professoras regentes, apesar de também reconhecerem as ações da disciplina de Educação Física na escola, resistem em atestar a repercussão dessas ações em suas aulas, como demonstra a seguinte narrativa:

Eles [os alunos] fazem todas as tarefas e tal [da Educação Física], mas não são muito de comentar. As temáticas vivenciadas nas aulas de Educação Física, como as danças e as brincadeiras, se manifestam sutilmente na sala de aula. Já observei o grafite, o hip hop e o rap, mas não vejo muita empolgação na maioria, não, em alguns, sim, mas não na maioria (VERA - professora da $4^{a} \mathrm{~A}$, grifo nosso).

Outras professoras, ao contrário, destacam em detalhes como esses movimentos provenientes da Educação Física repercutem em suas salas de aula:

Isso se manifesta muito nas minhas aulas. Já teve dia de eu ter que parar de dar aula, pois os meninos estavam ensaiando ali no canto o hip hop [atividade desenvolvida na

Educação Física]. (KÁTIA - professora da $4^{a} \mathrm{~B}$, grifo nosso).

Em outros encontros que participamos, vimos outras formas de relação com os conteúdos das culturas populares. Percebemos que os usos e apropriações desses conteúdos, articulados de forma dialógica com o aluno, conferiam, na interpretação dos professores, voz e autonomia para esses praticantes do cotidiano atuarem como produtores e não receptores passivos das culturas. Essa relação é evidenciada, nas narrativas dos professores:

Aqui, no espaço da escola, ele [aluno] se sente bem, em um ambiente onde ele pode se expressar e vivenciar aquilo que ele gosta (MARCOS - professor de Educação Física).

Eu considero que eles dão muito valor ao poder construir junto [...] (VERA - professora da $4^{\mathrm{a}}$ série $\mathrm{A})$.

Eu acho legal o envolvimento dos meus alunos e a liberdade que eles têm de chegar e dizer que $[. .$.$] desse modo não vai ficar legal [...] e$ propóem porque se interessam por aquilo que estão buscando aprender (KÁTIA - professora da $4^{\mathrm{a}}$ série $\left.\mathrm{B}\right)$.

Nas aulas de Educação Física, os professores se empenharam em ampliar o repertório de conhecimentos trazidos pelos alunos sobre a dança de ruaj. Abordavam o contexto histórico, as características do estilo da música, da dança, dos passos etc. Solicitavam pesquisas na internet e oportunizaram seus alunos demonstrarem o conhecimento que traziam sobre essa dança. Desse modo, esse saber adquiriu cada vez mais significado entre os alunos, pela oportunidade de demarcar seus espaços e suas produçóes.

O desenvolvimento dos saberes dos alunos se manifesta nas representações que eles possuem sobre a escola. Para eles, a escola é um espaço de construção do conhecimento que valoriza as suas produçóes. As letras dos rap e a dança de rua, produzidas nas aulas de Educação Física, demonstram essas representaçôes:

A escola quer o melhor com a gente construir 
Pela vida a lição

Um mundo diferente meu irmão

(Música composta pelos ALUNOS da $4^{\mathrm{a}} \mathrm{B}$ )

Aqui eu aprendo a lição

Respeito e união e assim eu me formo um

grande cidadão

Nossa escola tem muita criação

Arte, hip hop, leitura e educação

(Música de rua composta pelos ALUNOS da $\left.3^{\mathrm{a}} \mathrm{C}\right)$

A autonomia construída com os alunos foi percebida em outras circunstâncias do cotidiano. Nas aulas de Educação Física, os professores incentivaram os alunos a organizarem novas regras, para adaptar as atividades propostas às condiçôes físicas e materiais da escola. O conteúdo a ser desenvolvido na aula, bem como a maneira de abordá-lo, também foi construído no diálogo com a turma.

Pedimos que fizessem adaptaçôes das regras oficiais. Por exemplo, um time titular de futebol de campo [...] daria para realizarmos uma partida com duas equipes no nosso ambiente de aula? Caberia aos alunos responder e propor soluções (MARCOS - professor de Educação Física).

Ao promover a construção do conhecimento sobre as culturas populares pela dialogicidade com o aluno, as ações pedagógicas adotadas pelos professores, que motivam os alunos a opinar, sugerir, criar, num processo de conflito e transformação dos saberes que eles trazem (senso comum), rompem com as perspectivas pedagógicas que concebem os alunos pela sua negatividade, ou seja, por aquilo que eles não sabem e que precisa ser "transmitido" pelos professores. SANTOS ${ }^{27}$ afirma que não há sentido em criar um conhecimento novo e autônomo, em conflito com o senso comum, se esse conhecimento não visar a transformar o senso comum e nele se transformar. Para esse autor ${ }^{27}$, "[...] o que se pretende é um novo senso comum com mais sentido, ainda que menos comum" (p. 150).

Em consonância com as reflexões de SANTOS ${ }^{27}$, as ações empreendidas pela escola elevam o aluno à condição de praticante do processo de ensinoaprendizagem dos saberes relativos às culturas populares, pois estimula a dimensão estética das práticas e contribuem para que esse processo aconteça associado à produção de novos sentidos e significados ao senso comum (culturas populares).

Essa iniciativa pedagógica oferece condições para uma edificação do conhecimento, que contribui para a formação de sujeitos socialmente competentes. A construção do saber, pautado na produção de sentidos pelos praticantes do cotidiano, pressupóe romper com açóes pedagógicas que silenciam e escamoteiam os conflitos, que causam desequilíbrios e contradições na produção do conhecimento e que recusam os saberes locais ${ }^{27}$.

Segundo SANTOS ${ }^{29}$, é necessário construirmos "[...] uma ciência prudente para uma vida mais decente" e, para que isso aconteça, é preciso transformar o senso comum em um conhecimento com mais sentido e ressignificar o saber científico apropriado pela escola, contextualizando-o com as demandas locais (p.107). Essa perspectiva, proposta por $S_{A N T O S}{ }^{28}$, converge com o processo de circularidade cultural evidenciado na escola?.

Os dados produzidos explicitam que a escola valoriza os saberes populares que caracterizam a comunidade, pois engendra um processo em que as culturas locais adentram o espaço escolar e se inter-relacionam com a cultura mediada pela escola, produzindo um movimento de trocas recíprocas, que dinamiza o espaço escolar, potencializando as ações ali empreendidas. A EMEF C. J. é caracterizada pela diversidade de formações culturais, dado o quantitativo de alunos provenientes de diferentes cidades, Estados e regiões. Entretanto, longe de se constituir um obstáculo, essa diversidade é aproveitada pela escola, que modifica as suas ações para contemplar as diversas culturas que atravessam esse contexto. De acordo com GinZbUrG ${ }^{9}$, são os movimentos de inter-relações culturais que caracterizam a ação circular da cultura. Nessa escola, identificamos que o movimento de circularidade cultural é oportunizado nas ações dialógicas promovidas pelos professores que, ao valorizarem os saberes culturais da comunidade local, oportunizam ações que permitem o atravessamento de diferentes práticas culturais. Esses atravessamentos transformam a escola em um espaço e tempo de trocas, de experiências instituídas, sem que haja uma relação hierárquica de poder entre os saberes produzidos. Esse movimento de circularidade cultural não ocorreu somente entre os saberes populares e os saberes científicos sistematizados na escola, 
mas também entre as próprias manifestações das culturas populares, como demonstra a narrativa da professora de Educação Física:
Depois da Mostra Cultural, o professor Marcos sugeriu que a gente retomasse o trabalho sobre as culturas populares do Espírito Santo, iniciado no $1^{\circ}$ Trimestre, no decorrer do Projeto Lazer [...]. A proposta é que se consiga contextualizar o Espírito Santo de ontem e o Espírito Santo de hoje, no que se refere aos seus aspectos culturais, onde outras manifestações culturais, como as danças de funk e hip hop, invadiram esse espaço e hoje o caracterizam também [...]. A ideia é misturar a cultura que predominou no Estado ontem com as manifestaçōes culturais que se apresentam hoje. Um hip hop com o congo, por exemplo, e fazer essa mistura caracterizando a escola, construído como um

movimento da escola, no choque das culturas populares atuais com o erudito [...]. Quando essas culturas populares chegam dentro das aulas de Educação Física da escola, elas precisam ser contextualizadas [...]. A educação precisa ter seu papel de reflexão pedagógica (JOSI - professora de Educação Física).

Esse contexto dinâmico, de inter-relações, favorece para que o sujeito transforme aquilo que outrora parecia único, entendido como sua "marca", a sua identidade, em novas possíveis identidades. Como analisa $\mathrm{HALL}^{29}$, isso abala o conceito que temos sobre nós próprios como sujeitos integrados: "[...] não existe uma cultura popular íntegra e autônoma, situada fora das relações de poder e de dominação cultural". Existe, pois, uma cultura popular influenciada por diferentes culturas, que vão constituir diferentes identidades (p. 254).

\section{Notas}

a. O termo classe está apresentado entre aspas para designar a forma como foi empregado pelo autor utilizado nesse estudo? .

b. O conceito de consumo produtivo, desenvolvido por CERTEAU ${ }^{7}$, preconiza que os bens culturais não são consumidos passivamente pelos praticantes do cotidiano. Para ele, há uma estética da recepção em que os indivíduos alteram taticamente as mensagens culturais veiculadas por diferentes agências de socialização, como o governo, a escola e a mídia.

c. A noção de redes está associada às relaçóes que geram o conhecimento. Trata-se de uma metáfora utilizada para indicar que o conhecimento é produzido nos diversos contextos cotidianos pela ação coletiva dos atores sociais ${ }^{11,13}$.

d. Táticas e estratégias são conceitos formulados por CERTEAU ${ }^{7}$, que pressupóem que há uma organização de métodos e procedimentos que visam a controlar, dominar e que são aplicados aos contextos sociais, políticos, culturais etc. A esse conjunto de regras e normas o autor denomina de "estratégia", ao passo que outros procedimentos, que nascem da recusa ou subversão a essa disciplina e organização, são denominados "táticas".

e. O sentido que atribuímos à narrativa se constitui a partir do conceito de "enunciaçáo", proposto por CERTEAU ${ }^{15}$, que se configura como a "fala em ato". Nessa perspectiva, a fala só tem sentido se considerado o contexto no qual ela foi produzida.

f. A EMEF C. J. implantou o ensino de nove anos em 2010, entretanto as turmas matriculadas no antigo formato de seriação seguirão dessa forma até a conclusão do processo em curso.

g. Para Morin ${ }^{16}$ “[...] tudo se entrecruza, se entrelaça para formar a unidade da complexidade; porém, a unidade do 'complexus', não destrói a variedade e diversidade das complexidades que o teceram.” (p. 176)

h. Para Morin ${ }^{16}$ "[...] tudo se entrecruza, se entrelaça para formar a unidade da complexidade; porém, a unidade do 'complexus', não destrói a variedade e diversidade das complexidades que o teceram.” (p. 176)

i. A dança de rua, como é popularmente conhecida no Brasil, se caracteriza como um estilo de dança em que os alunos se reúnem em círculos, demonstram habilidades de movimentos corporais e de acrobacias, ao som de músicas com marcação forte.

j. O mergulho no cotidiano da escola nos possibilitou identificar que o "movimento hip hop", desenvolvido pela professora de Educaçáo Física, é caracterizado pela dança de rua, pelo rap, que são as letras das músicas que trazem reflexóes e apontamentos acerca da realidade social, que chamaremos por "música de rua”, e pelo grafite, que é a arte de se expressar por meio de desenhos estilizados. Essas manifestaçóes caracterizam as culturas populares da comunidade local e são ressignificadas no contexto escolar.

k. Adotaremos nomes fictícios para a instituição e os sujeitos envolvidos nesse estudo. 


\begin{abstract}
Falta título em inglês

Objective understanding the uses and appropriations that students and teachers of a public school make of the popular cultures in the context of the Physical Education classes and in public everyday of a school. To do so, it used the Study with the Everyday Life as theoretical-methodological assumption, which data was produced with the different practitioners present in the context shared, teachers, students, pedagogical team, local community and it uses data from different sources, like field diary, narratives, interviews and other. The result denotes the following uses and appropriations: relation between the local culture with the global one; valorization of the autonomy and the students' participation in the knowledge construction; production of the "net knowledge"; sensation of belonging to the school community.
\end{abstract}

KEYwords: Studies of the Everyday; Networks of Knowledge; Elementary School; Role of the Student.

\title{
Referências
}

1. Veiga-Neto A. Cultura, culturas e educação. Rev Bras de Educação. 2003;(23):5-15.

2. Moreira AFB, Candau VM. Multiculturalismo: diferenças culturais e práticas pedagógicas. Petrópolis: Vozes; 2008.

3. Zandomínegue BAC, MELLO AS. A cultura popular nas aulas de educação física. Curitiba: Appris; 2014.

4. Faria EL. O esporte nas aulas de educação física. Pres Pedagógica. 2001;7(41):19-31.

5. Faria EL. Conteúdos da educação física escolar: reflexões sobre educação física e cultura. Rev Min Educ Fís. 2004;12(2):124-142.

6. Oliveira SA. Reinventando o esporte: possibilidades da prática pedagógica. Campinas: Autores Associados; 2001.

7. Certeau M. A invenção do cotidiano: artes de fazer. Alves EF, tradutor. Petrópolis: Vozes; 1994.

8. Certeau M. A cultura no plural. Campinas: Papirus; 1995.

9. Ginzburg C. O queijo e os vermes: o cotidiano e as idéias de um moleiro perseguido pela inquisição. São Paulo: Companhia da Letras; 1987.

10. Ginzburg C. Mito, emblemas e sinais: morfologia e história. São Paulo: Companhia das Letras; 1989.

11. Ferraço CE. Ensaio de uma metodologia efêmera: ou sobre as várias maneiras de se sentir e inventar o cotidiano escolar. In: Oliveira IB, Alves N, organizadoras. Pesquisa no/do cotidiano das escolas: sobre redes de saberes. Rio de Janeiro: DP\&A; 2001. p. 101-117.

12. Alves N. Espaço escolar e suas marcas: o espaço como dimensão material do currículo. Rio de Janeiro: DP\&A; 1998.

13. Alves N. Decifrando o pergaminho: o cotidiano das escolas nas lógicas das redes cotidianas. In: Oliveira IB, Alves N. Pesquisa no/do cotidiano das escolas: sobre as redes de saberes. Rio de Janeiro: DP\&A; 2001. p. 14-38.

14. Borges CJ. História da Serra. Serra: Canela Verde; 2003.

15. Certeau M. Teoria e método no estudo das práticas cotidianas. In: Szmrecsanyi MI, organizador. Cotidiano, cultura popular e planejamento urbano. [Anais do encontro]. São Paulo: FAU/USP; 1985. p. 3-19.

16. Morin E. Epistemologia da complexidade. In: Shinitimas D, organizador. Novos paradigmas, cultura e subjetividade. Porto Alegre: Artes Médicas; 1996. p. 174-288.

17. Carvalho JM. Pensando o currículo escolar a partir do outro que está em mim. In: Ferraço CE, organizador. Cotidiano escolar, formação de professores (as) e currículo. São Paulo: Cortez; 2005. p. 94-111.

18. Abib PRJ. Cultura popular, educação e lazer: uma abordagem sobre a capoeira e o samba. Práxis Educativa. 2006;1(1):5866.

19. Marques IA. Ensino de dança hoje: textos e contextos. São Paulo: Cortez; 1999.

20. Brasileiro LT. O conhecimento no currículo escolar: o conteúdo dança em aulas de educação física na perspectiva crítica [Dissertação]. Recife (PE): Universidade Federal de Pernambuco, Centro de Educação; 2001.

21. Brasileiro LT. O conteúdo dança em aulas de educação física: temos o que ensinar? Rev Pensar a Prática. 2003;(6):4558.

22. Brasileiro LT. Diálogos necessários sobre dança e educação física. Anais do 7o Congresso Espírito-Santense de Educação 
Física; 2007; Vitória. Vitória: DEF/UFES; 2007. p. 18-28.

23. Fiamoncini L. Dança na educação: a busca de elementos na arte e na estética [Dissertação]. Florianópolis (SC): Universidade Federal de Santa Catarina, Faculdade de Educação; 2003.

24. Morandi CSD. Passos, compassos e descompassos do ensino de dança nas escolas [Dissertação]. Campinas (SP): Universidade Estadual de Campinas, Faculdade de Educação; 2005.

25. Bracht V. A constituição das teorias pedagógicas da educação física. Cad Cedes. 1999;19(48):69-88.

26. Bourdieu P. O poder simbólico. Lisboa: Difel; 1989

27. Santos BS. Introdução a uma ciência pós-moderna. Rio de Janeiro: Graal; 1989.

28. Santos BS. Conhecimento prudente para uma vida decente: um discurso sobre as ciências revisitado. São Paulo: Cortez; 2004.

29. Hall S. Da diáspora: identidades e mediaçóes culturais. Belo Horizonte: Editora da UFMG/Brasília; 2003.

ENDEREÇO DE CORRESPONDÊNCIA:

Bethânia Alves Costa Zandomínegue Av. Fernado Ferrari, s/n - Bairro Goiabeiras

Vitória - Espírito Santo - BRASIL

CEP: 29075-910

E-mail: bethabill@yahoo.com.br; bethania.costa@uvv.br
Submissão: 09/02/2016

Revisado: 30/01/2017

Aceito: 29/12/2017 